\title{
OS TELEFONES CELULARES E A APRENDIZAGEM COLABORATIVA NA SOCIEDADE DE SERVIÇOS: O DESDOBRAMENTO DA SOCIEDADE DA INFORMAÇÃO EM REDE
}

\author{
Benedito Medeiros Neto \\ Universidade de Brasília \\ medeirosneto@unb.br
}

\begin{abstract}
Resumo
Este artigo trata de questões recentes da Sociedade da Informação em Rede no Brasil, quando dispositivos móveis, como o celular, chegam às mãos de pessoas, principalmente as com carência de recursos materiais e cognitivos, seja pela falta de capacitação e mediação ou acesso restrito às informações de utilidade pública. No estudo identificou-se que os novos dispositivos multifuncionais apontam para mudanças e transformações nas atividades pessoais, nas relações interpessoais e nas comunicações locais e globais. Por outro lado, percebe-se que segmentos econômicos, como Agricultura, Indústrias e Serviços, passam por mutações profundas, e em um futuro próximo, os Serviços se tornarão mais proeminentes e predominantes devido à economia digital. No estudo, comprova-se que a cognição junto com Cultura, em especial a Digital, associadas à Educação, levam os usuários à aprendizagem continuada, mas apenas quando a todos é facilitado a comunicação ubíqua e a computação pessoal dos celulares, ao mesmo tempo nos lares e ambientes de trabalho e/ou escolar. A sociedade caminha, não para um mundo de maravilhas com presença das TIC mediando as atividades do homem, mas ao contrário, para uma série de questões e disputas por bens e serviços, requerendo o poder moderador e regulamentador do Estado nas questões do trabalho, educação, saúde e segurança, pelo menos. Finalmente, mostra-se que o protagonismo, no Século XXI, permitido pela revolução informacional e das mídias comunicacionais, possibilita representatividade política, a reivindicação da falta dos serviços básicos para todos, e a possibilidade da melhoria da qualidade de vida, podendo levar ao fortalecimento de uma Sociedade de Serviços.
\end{abstract}

Palavras-chave: Dispositivos móveis. Convergência. Ubiquidade. Industria, Agricultura, Economia digital.

\section{CELL PHONES AND COLLABORATIVE LEARNING IN THE SOCIETY OF SERVICES: THE DEVELOPMENT OF THE NETWORK INFORMATION SOCIETY}

\begin{abstract}
This article approaches recent questions of the Network Information Society in Brazil, when mobile dispositive, such as cell phone, arrives in people hands, principally to the ones with lack of material or cognitive resources, due to lack of capacitation and mediation, or restricted access to public utilities informations. In this study, it was identified that new multifunctional appliances show changes and possibility of transformation in the personal activities, as well as in the interpersonal relations and in the local and global communications. On the other hand, it is perceived that economic segments, such as Agriculture, Industries and Services, go through profound mutations, and in a near future, the Services will become more prominent and predominant due to the digital economy. In the study, it is stablished that cognition together with culture, specially the digital, associated to Education, lead the users to continued learning, but only when the ubiquitous communication is facilitated to all, as well as the cellphone personal computation, in the same time in homes, work/school environments. The society walks, not to a marvelously world with the TIC presence, mediating person activities, but in contrary, to a series of questions and disputes for goos and services, requiring from State the moderate
\end{abstract}


and regulatory power, related to work, health, and security, at minimum. Finally, the study shows the protagonism, in the XXI Century, allowed through the informational revolution and the communicational medias, making possible the political representativeness, the lack of basic services claim for all, and the possibility of quality life improvement, leading to the strengthening of a Service Society.

Key-words: Mobile devices. Convergence. Ubiquity. Industry, Agriculture, Digital economy.

\section{Introdução}

Nos anos 1990, os microcomputadores (computadores pessoais, PC) facilitaram o homem a lidar com um maior volume de dados e informações. Até então, a Internet trouxera o acesso à informação, lazer, cultura e a serviços públicos, com os governos eletrônicos, para as classes média e alta. Em contraste, nos dias de hoje, classes menos favorecidas têm acesso às diversas facilidades quando equipamentos móveis (um celular, por exemplo) chegam as suas mãos. Assim, os celulares trazem aos usuários a computação pessoal e a comunicação ubíqua, permitindo que o conhecimento esteja mais perto deles, tanto fazendo onde o indivíduo esteja: em casa, no trabalho ou em uma área rural.

Assite-se à presença, a cada mais intensa, do celular na mudança dos contextos social, cultural e econômico. Também não importa o modo de conexão: ondas eletromagnéticas, fio de cobre, fibra ótica ou cabo subaquático no Amazonas ou no Oceano Atlântico. Cada dia mais, o indivíduo estará mais conectado ao mundo ou vivendo em um ciberespaço cuja dimensão, às vezes, os menos avisados não têm consciência (LEMOS, 2014; LÉVY, 2014).

O fato é que a chegada do primeiro computador, na segunda década desse século, e depois, da Internet nas casas de indivíduos da classe $\mathrm{C}$, atendeu às necessidades do jovem, que antes buscava conectar-se à Internet nas lan houses. Esse jovem viu seu universo de relacionamentos sociais e de valores culturais se ampliarem mais e mais. A possibilidade de acessar os amigos nas redes sociais transformou a forma de viver em comunidades, fazendo que os ambientes virtuais de aprendizagem e de lazer estivessem juntos e misturados, a qualquer hora do dia, colocando os usuários sob uma nova perspectiva de vida (MEDEIROS NETO, 2012).

\section{A Sociedade Conectada no Brasil, América Latina e Mundo}

A sociedade denominada de modernidade líquida ou fluída (BAUMAN, 2001), também designada por outros autores como pós-moderna, última modernidade, hipermoderna ou apenas hiper, é marcada por uma comunicação ubíqua, pela expansão da mobilidade das 
redes wi-fi e on-line, e pelo crescente número de dispositivos móveis. A pesquisa Visual Networking Index ${ }^{1}$ da Cisco vaticina que o mundo terá 4,1 bilhões de pessoas conectadas em 2020, a maioria consumindo vídeo em celulares (smartphones). O tráfego móvel global crescerá sete vezes entre 2016 e 2021, passando de 87 EB para 587 EB. Se comparado com 2011, é um crescimento de 122 vezes em dez anos.

O predomínio da Internet com os celulares levou os pesquisadores a buscarem métodos para avaliarem os procedimentos cognitivos nesses ambientes marcados pela realidade aumentada e por forte interatividade das pessoas. Observa-se um significativo interesse dos pesquisadores pelas abordagens empíricas a respeito do uso das TIC, consubstanciado nos ensaios de avaliação do ensino não presencial, na convivência cultural e na crescente participação política. Entretanto, há um lado negativo nesse processo expresso por críticas aos jovens que não largam o game, e utilizam tecnologia para meros fuxicos na rede social, expondo suas intimidades.

Os investigadores do ciberespaço levaram um tempo para identificar metodologias que fossem eficientes e práticas e que permitissem coletar e analisar dados compatíveis com seus problemas de pesquisa de modo mais rápido que a tradicional pesquisa social. Novas visões teóricas ajudaram a superar barreiras em países desenvolvidos, movimento ainda incipiente nos países pobres da América Central e Latina. Os pesquisadores mudaram seu olhar e sua apropriação de novas metodologias quanto à pesquisa empírica, à construção de amostras, e à análise rápida e automática de dados disponíveis e abertos na Internet (FRAGOSO; RECUERO; AMARAL, 2011).

A recente promissora conexão das coisas pela Internet já é uma realidade, uma vez que o número de dispositivos deverá subir dos atuais 16,3 bilhões para 26,3 bilhões já em 2020, considerando as conexões máquina a máquina (M2M) e a Internet das Coisas (IoT). Mesmo nos países que hoje padecem com outras carências básicas, esses indicadores serão expressivos. Como consequência, volta a evidenciar-se a necessidade de investigações e pesquisas que aprofundem nosso entendimento desse complexo ambiente emergente, híbrido, fluído e convergente.

\section{O celular no contexto da economia digital}

\footnotetext{
${ }^{1}$ Em junho de 2016, a Cisco publicou a previsão Complete VNI Global IP Traffic Forecast, para o período 20152020. Disponível em: http://www.cisco.com/c/en/us/solutions/service-provider/visual-networking-indexvni/index.html
} 
Os progressos atingidos pelas inovações tecnológicas em curso e a universalização dos serviços de telecomunicações, juntamente com o tratamento dos dados em grandes centros (big data) são acompanhados pelo crescente número de repositórios de informação em nuvem oferecendo novos serviços e expansão das redes de computadores. Por outro lado, a concorrência de vários competidores, principalmente as produtoras de conteúdo de imagem e vídeo comprometem, gradualmente, os recursos de telecomunicações. No entanto, o marketing e a receita desses serviços estão favorecendo com a interatividade dos usuários empresas como Youtube, Facebook, Google, Microsoft, Samsung, entre outras.

Com a universalização dos celulares e a presença das redes, tem-se a expectativa de que, em pouco tempo, maior número de pessoas, em qualquer lugar, a qualquer hora e por meio de qualquer dispositivo terá acesso aos serviços de educação, saúde, lazer e segurança, com a corresponde cobrança por maior qualidade do atendimento desses serviços (CASTELLS et al., 2007).

A posse de um celular inteligente como conquista social e econômica e como parte inerente â vida dos jovens permitiu que os comportamentos desses usuários fossem investigados e comparados com a posse do computador a partir década de 2000, dados esses referendados pelo IBGE, pelo Comitê Gestor da Internet e pelas operadoras de telecomunicações.

Nesse sentido, muito se tem investigado sobre os jovens e, mesmo adultos, como novos portadores de dispositivos móveis, até mesmo em áreas de baixa renda. Como e o que mudou em termos de comportamentos se comparado ao que era antes observado quanto ao acesso ao computador, na escola ou em casa? Os ganhos de aprendizagem dos indivíduos eram facilmente percebidos ou verificados antes, quando os objetos de pesquisa eram os frequentadores de telecentros e lan houses das periferias dos grandes centros e de pequenas cidades da América Latina (PASSARELLI, 2014).

\section{A Educação como a expansão de conteúdos e mobilidade}

A produção exponencial de conteúdos leva os pesquisadores a olharem um pouco mais à frente, vislumbrando os possíveis impactos que outras mudanças advindas do volume de dados tratados pelas TIC podem provocar em áreas que até então foram preservadas dessas transformações. Na visão de Manuel Castells (2013), os movimentos sociais mais recentes, 
com o suporte da sociedade em rede, expõem as contradições fundamentais de nosso mundo e potencializam uma nova forma de conviver em comunidade e em sociedade.

Mais e mais são necessárias reformulações teóricas, epistemológicas e metodológicas para lidar com a dificuldade de acesso seletivo, a organização e o arquivamento da informação, pois a disponibilização está presente em vários canais e mídias e as bases de dados sediadas em várias partes do mundo, principalmente, nos data centers dos USA, Europa e Ásia. Além disso, o celular na mão de mais da metade da população mundial, com mediação das outras TIC, multiplica a produção de conteúdo. Os serviços como a educação, saúde, e economia, agora digital, por exemplo, ficarão em constante tensão frente às areias movediças da sociedade em rede (PASSARELLI, 2010; CASTELLS et al., 2007).

\section{Mobilidade dos celulares na Educação}

Nos últimos 20 anos, o uso de computadores nas escolas e laboratórios de escolas públicas - ainda insuficientes em número e não satisfatório na apropriação - fez um caminho sem volta. Alguns trabalhos de avaliação mostraram os ganhos e os atropelos dessa utilização (MEDEIROS NETO; MIRANDA, 2015). Mas, na primeira década desse século, a mensuração e a avaliação ficaram mais difíceis para pesquisadores, em razão de que os portadores de celulares desenvolveram novas competências em informação pela pressão da necessidade de sobrevivência, o que é potencializado pela ubiquidade desses aparelhos.

O advento das tecnologias móveis tem criado oportunidades de promover a aprendizagem com auxílio de dispositivos como telefones celulares, laptops, tablets e notebooks (m-learning). No projeto, os futuros mediadores, universitários moradores das regiãos administrativas do FG foram capacitados em TIC por bolsista do Programa Jovem Talento/MEC, e para tanto, tabletes foram dispositivos móveis emprgados como instrumento de ensino.

Coletivamente, esse tipo de aprendizagem por dispositivos móveis é chamado $\mathrm{m}$ learning, que pode ser pensado como um subconjunto de e-learning (onde a entrega de conteúdo é baseada na Web e no gerenciamento de aprendizagem (FRANÇA; STIUBIENER, 2015). Nesse caminhar o usuário pode contar, ou não, com ajuda de colegas de trabalho ou de familiares. A inteligência coletiva do seu grupo mais próximo marca a fase inicial de sua aquisição de competências em TIC; depois, ele caminhará sozinho de modo a obter serviços disponíveis nas aplicações da Internet (APP), além da fronteira da simples comunicação de voz de seus artefatos eletrônicos (PIENIZ; SILVEIRA, 2011). Com certeza os usuários 
tentam superar suas deficiências de habilidades com os dispositivos móveis e as TIC a todo custo. No entanto, permanecem dúvidas entre os professores e pedagogos mais tradicionais quanto a efetividade do smartphone como instrumento de ensino.

A comunicação da informação mais rápida por muitos usuários altera o dia-a-dia de todos. Isso, portanto, deve ser objeto de estudos de pesquisadores de campos transdisciplinares para uma possível interdisciplinaridade entre Informação, Comunicação e Computação, nas universidades, nas bibliotecas, centros de pesquisas e, também, nas empresas. Mas existem questões de base como aponta o pesquisador Rafael Capurro, da Escola Superior de Mídias de Stuttgart:

\begin{abstract}
¿Hasta que punto podemos hablar de una crisis de la lectura en las instituciones educacionales actuales? ¿Tiene esto que ver con el predominio de Internet y los nuevos medios como lo creen algunos críticos pesimistas y conservadores? (CAPURRO, 2010).
\end{abstract}

O contexto é movediço e não há dúvidas, nos países desenvolvidos, de que a resposta a essas perguntas levará governos, indústria e mercado a se movimentarem. Presentemente, pensadores e filósofos de centros de competências se debruçam sobre essas questões, em todas as partes do mundo, pesquisadores refletem sobre os impactos na sociedade em um horizonte bem próximo, por exemplo 2020.

No ensino do uso das TIC de maneira não formal, ou popular, os mediadores, universitários e líderes comunitários gostariam de deixar de lado a inclusão digital como foi definida e praticada na década passada, passando a cuidar das literacias via dispositivos móveis (PASSARELLI, 2014; MEDEIROS NETO, 2012).

\title{
4 Traço da Internet das Coisas
}

A perspectiva da Internet das Coisas (Internet of Things - IoT) deixou de ser apenas um objeto de pesquisa na academia para concretizar-se em promissora possibilidade de mercado. Primeiro pela possibilidade de o número de bens conectados explodir, somado à universalização do celular e à presença nos lares e no trabalho dos artefatos inteligentes (smartphones). Mas, qual o contingente de engenheiros de computação será necessário? Como as legislações acompanharão a regulamentação? Aonde isso levará? Entre outras coisas, “...a uma realidade não esperada pelos mais distraídos, e a uma atenção dobrada pelos que falam de alienamento do ser humano à interface com as telas das máquinas" 
(JUNQUEIRA; PASSARELLI; GUZZI, 2014). Em segundo, pela crescente ubiquidade dos dispositivos de acesso.

O fato é que a Internet das Coisas (IoT) recebe, a partir de 2014, atenção dobrada de vários setores da economia, e.g., os governos, o mercado de serviços e a indústria de TI. São vários os sentidos possíveis ao se abordar a IoT, mais comumente descrita como um ecossistema de tecnologias que monitora o estado de objetos físicos conectados. Para iniciar as trocas de dados significativos, a base, ainda, é de trocas de dados por redes IP (Internet Protocol), seguidas por camadas de softwares intermediários e aplicações. Nas palavras de Passarelli (2014, p. 14):

\begin{abstract}
A IoT pode então ser definida como uma conexão em rede de pessoas, processos, dados e coisas compartilhando e utilizando novas informações e permitindo obter benefícios econômicos para as empresas, melhores formas de educar e cuidar das pessoas e melhor qualidade de vida.
\end{abstract}

Os temas recorrentes em todas as definições da IoT incluem objetos inteligentes, comunicação máquina a máquina (M2M), tecnologias de RF (radiofrequência), e um hub central de informações. Já é fato comprovado que houve um aumento de usuários produtores e consumidores (prosumer) de informação. Uma questão muito maior do que foi a do uso de nome de usuários (login) e de senhas (password) de acesso aos sistemas de informação sensíveis, de dez anos atrás.

$\mathrm{O}$ acesso generalizado da $I o T$, em todo o mundo, devido ao crescimento de objetos ditos inteligentes, potencializado pelo acesso ao celular (smartphone) e pela disponibilização da banda larga e wi-fi, alargou os territórios e possibilitou o aparecimento de novas fronteiras da mobilidade informacional. E junto com essa generalização, veio a exponencial necessidade da estruturação e do trato da informação que pode originar a perda do controle das informações (MEDEIROS NETO; MIRANDA, 2015).

\title{
O outro lado (da moeda) da tecnologia
}

Nem só de boas novas e sucessos vive a chegada das TIC. Temas centrais ainda não colocados em pauta, mas que ganharão corpo nas próximas décadas, serão questões como 
empregabilidade $^{2}$, educação e renda. Ficando claro para alguns que haverá, inevitavelmente, em alguma medida, a substituição do trabalho humano pelo de máquinas.

Se de um lado a facilitação do acesso à rede $(W e b)$ via celular pode vir a propiciar as condições técnicas para uma maior distribuição (mais abrangente e democrática) de conhecimentos e informações, de outro será necessária uma disciplina de estudos do uso e da apropriação das TIC. A população brasileira deve ser esclarecida e preparada para conseguir alcançar, assimilar e usufruir de todos esses conhecimentos. Novas políticas públicas deverão ser legisladas e debatidas com a sociedade. A educação deve ser ampliada nos níveis fundamentais, estudar mais apropriadamente e mais profundamente serão prioridades. Os indicadores internacionais falam melhor sobre isso. E a tecnologia não é uma tábua de salvação que traz caminhos mais fáceis ou atalhos nesse processo. A propósito, parte da população brasileira não está consciente do cenário que envolve os fatos e carece de maior disciplina para organizar seus afazeres, educação e trabalho.

Esses enormes avanços e a automatização de funções maçantes ou funções de maior esforço físico irão melhorar a qualidade de vida de quem vier a se beneficiar desses avanços tecnológicos (e.g., a classe média das sociedades centrais do capitalismo mundial). De outra maneira, a mão de obra substituída possivelmente será arremessada para a mais profunda miséria. Os substituídos serão os novos excluídos - todos eles mantendo, a partir de então, o gosto amargo de já ter experimentado a inclusão.

Como acomodar tanta desigualdade social e desemprego, que inclusive já está atingindo os países centrais de nosso sistema? No contexto local, como enfrentar esses desafios, num ambiente de educação deficiente em que estamos hoje? Onde encontraremos a quantidade e a qualidade de professores, e especialistas, de gestores e políticos para fomentar a competitiva economia digital em um país de analfabetos funcionais como o nosso? As respostas não são simples e devem ocupar boa parte das pesquisas nos anos vindouros.

\footnotetext{
${ }^{2}$ O Engenheiro e Presidente da BRISA (http://www.brisa.org.br/) proferiu, no CIC/UnB, a Palestra: Construindo um caminho de sucesso no Mercado de Trabalho, Novembro de 2014. A alocução focou no contexto, nas expectativas e posicionamentos profissionais num mercado de trabalho de TIC em constante evolução (ou constante "revolução"). O palestrante buscou identificar quais são as expectativas atuais das empresasquando recrutam profissionais da área de TIC; discutiu o planejamento de carreira do profissional de TIC, num mundo cuja tendência é de elevação crescente da rotatividade da força de trabalho; discutiu e debateu estratégias para que os jovens talentos alcancem o almejado sucesso profissional.
} 


\section{Perspectivas do celular na Economia Digital}

Uma das marcas da sociedade dessa segunda década do Século XXI é a presença de dispositivos móveis nas mãos das pessoas, notadamente, aqueles artefatos que facilitam a comunicação, as relações interpessoais, os acessos às informações, aos serviços públicos e privados disponibilizados pelos mercados, governos e organizações. $\mathrm{O}$ uso das facilidades de telecomunicações dedicadas a dados, imagens, vídeos e sons, é crescente e cada vez proporcionalmente maior do que aquele dedicado à voz, antevendo-se a possibilidade de saturação do tráfego nas redes de telecomunicações.

A Internet vai se tornando o principal meio para permitir o acesso à informação e ao conhecimento, sendo um canal para formação da inteligência coletiva. A Web Semântica será a ponte para se chegar aos serviços de forma mais ampla e racional, no pensamento de Pierre Lévy, (2014). Ao mesmo tempo, a oferta ou disponibilização da informação para a população deve ser uma questão de política de estado, com grande ênfase na governança e na regulação. Por exemplo, o marco regulatório da Internet em cada país passa a ser fundamental para a exploração do mercado pelos provedores e prestadores de serviços, sendo o papel dos governos resguardar os mínimos direitos dos cidadãos (MEDEIROS NETO, 2012, p. 27).

As TIC, com preponderância do acesso e uso da Internet, foram consideradas nos últimos 20 (vinte) anos como promotoras de desenvolvimento econômico e social, em países subdesenvolvidos e proporcionadoras de benefícios políticos e de bem-estar para o cidadão nos países desenvolvidos, possibilitando o alcance de uma cidadania plena. Mas, os dispositivos móveis estão encurtando as distâncias, tendo sido possível observar esse fenômeno em comunidades frágeis e vulneráveis, porém não se deve generalizar que sempre haverá melhoria da cidadania em todas as camadas sociais.

As prospecções futuras devem apontar para os desafios de ordem tecnológica e aqueles inerentes ao desenvolvimento dos dispostos móveis na economia digital, em vista do traço marcante destes dispositivos móveis ser fator dinamizador de Ambientes Virtuais de Aprendizagem (AVA), por meio de aplicativos grátis da Web. Quanto ao ensino, devem ser consideradas as resistências à adoção de novas tecnologias, as práticas de ensino e aprendizagem, bem como as de ordem pedagógica e contextual ou social.

Espera-se um aumento da implementação de Ambientes Virtuais de Aprendizagem (AVA) apoiados nas literacias via dispositivos móveis, a incorporação do sistema de avaliação automática do ambiente de aprendizagem e uma maior preocupação com as usabilidades das interfaces e das ferramentas pedagógicas. 


\section{Um olhar além da Sociedade da Informação em Rede}

A passagem da sociedade pós-industrial para a pós-moderna, foi abordada nos capítulos 1 e 2 . Nos capítulos seguintes, foi possível identificar o que aconteceu depois. Um equívoco ocorre quando se entende que teríamos uma evolução sequencial da Sociedade Industrial, que estava fundamentada apenas no aspecto da força de trabalho, para uma Sociedade de Serviços, ou seja, a transferência de parte da mão-de-obra do chão da fábrica para os escritórios. Na época, entendia-se que o rápido crescimento de oportunidades para profissionais liberais de nível superior e de nível técnico impulsionaria a mudança na sociedade, posto que não existia a presença de fatores como a globalização, as inovações tecnológicas, as formas de relacionamentos e outros fatores que alteraram a forma de viver nos últimos 70 anos (KUMAR, 2006).

\section{Sociedade da Informação em Rede}

Entretanto, a mudança não se deu de uma forma direta e levou bastante tempo para acontecer e, ainda, de forma diferente do esperado. O certo é que viveu-se em uma Sociedade pós-Industrial por um bom tempo. No entanto, a transição não se deu de forma tão direta e rápida como se esperava; somente após longo período é que as primeiras previsões da predominância dos serviços se confirmariam; enquanto isto, formaram-se novas relações mediadas pelas TIC entre os cidadãos. O mercado de trabalho diversificou-se, e os governos e os cidadãos ficaram marcados pelo regime de informação. Os fluxos crescentes de informação suportados pelas redes de computadores ampliaram 50 vezes nos últimos 30 anos: o fato é que se vive uma Sociedade da Informação em Rede. Mais uma vez, não se trata de olhar para o futuro e rotular uma nova época da sociedade pós-Rede, onde o conhecimento é cada vez mais incerto e plural na visão de modernos pensadores (CUEVAS-CERVERÓ et al., 2014).

A agricultura, nesse período, seguiu um caminho mais rápido do que nos 5 (cinco) séculos anteriores. Por exemplo, a mecanização dos campos de plantio é uma realidade, e existem sempre novos produtos de proteínas, carbo-hidratos e gorduras resultantes da indústria alimentícia produzidos com forte uso de Tecnologia da Informação. A concorrência internacional muda a paisagem do campo. Em breve se vai assistir a agricultura brasileira enfrentar uma nova concorrência: outros países, também privilegiados pelo clima (por exemplo, os países africanos), e que são menos arredios ao capital externo que têm recebido 
investimentos tecnológicos maciços. Enquanto nossos dirigentes sindicais se perdiam em questões ideológicas em relação ao uso do capital, a atenção da economia de mercado global, com a crescente presença dos sistemas de comunicação, era focada em novos atores, segundo o engenheiro Paulo Toledo, o presidente da Brisa - http://www.brisa.org.br/ (2015).

\section{Vivendo em uma sociedade pós-Industrial}

$\mathrm{Na}$ verdade, não se trata apenas de designar uma nova versão da indústria e da agricultura como sendo mais avançadas. Além dos avanços inquestionáveis, os serviços nas mais diversas atividades humanas, nos últimos 40 (quarenta) anos, consolidou a Sociedade da Informação, a Sociedade do Conhecimento e a Sociedade em Rede Mas existe um pano de fundo em mutação. "Há uma crise do humanismo diante dos desenvolvimentos tecnológicos que, às vezes provoca muita angústia e incerteza social, política e legalmente"3 (CAPURRO, 2010).

Caminha-se para uma pós-Sociedade da Informação em Rede com uma população crescendo a taxa menores, mas com ascendentes necessidades de serviços básicos e de luxo, mesmo a despeito das crises econômicas e das disputas ideológicas; tanto no Brasil quanto em relação ao restante do mundo.

Os serviços crescem com a universalização de algumas tecnologias e com o uso intensivo dos sistemas da informação, agora mais inteligentes e globais. E o que se tem hoje? Ganham espaços na sociedade atual, apoiadas em tecnologias, a agricultura pós-Terceira Revolução, a Indústria pós-Segunda Revolução e os serviços após a sua Primeira Revolução. A agricultura vai se diferenciando em familiar e em corporativa, as exigências de preço, de automação e de qualidade fazem a indústria ficar na mão de poucos grupos. Outro fato é que fica cada vez mais claro que apenas utilizar uma facilidade ou bem pode ser melhor do que comprar e mantê-lo para usufruir depois. Um terceiro fato inquestionável é que os serviços cresceram com a infraestrutura das redes de telecomunicações e as facilidades da Tecnologia da Informação. Contudo, as novas tecnologias, que permitem expandir o acesso aos serviços, podem impor limites a quem tem pouco acesso à tecnologia ou carece de habilidade de uso.

\footnotetext{
${ }^{3}$ Tradução livre de: Hay una crisis del humanismo frente a los desarrollos tecnológicos que provoca a veces mucha angustia o incertidumbre a nivel social, político y legal. (CAPPURRO, 2014).
} 


\section{Fatores atuais que levam à Sociedade de Serviços}

Antes de direcionar nossa reflexão para a fundamentação da Sociedade de Serviços com base na universalização das tecnologias, na inovação e nos fluxos de informação, faz sentido rever pelo menos duas proposições dignas de comprovação em relação a ela. Isso porque a economia digital deve explorar novos nichos de mercado antes adormecidos, e comunidades isoladas farão parte de mercados de serviços em aspectos bem distintos dos atuais.

O vetor cultural de um país ou mesmo de uma comunidade pode provocar mudanças na expectativa dos consumidores de bens e serviços, de conteúdos, atingidos por enorme variedade de fluxo e oferta de materiais descartáveis, ou de curta duração. Por outro lado, abrem-se as possibilidades de mais mudanças com interação nas redes sociais, e participação de atores em rede interessados em conhecer e consumir os serviços que existem, e com uma expectativa de consumo futuro impactado pelo digital.

\section{Na perspectiva da convergência, ubiquidade e hibridismo}

Depois os primeiros passos da digitalização das telecomunicações, há mais de 50 anos, a digitalização fortaleceu a aproximação entre a Computação, a Informática, a Teleinformática, a Tecnologia da Informação (TI) e as Telecomunicações. Essas áreas estão tão imbricadas que não é fácil distingui-las mais. Por outro lado, observa-se nitidamente que, no final desta segunda década deste século, as redes de telecomunicações e a computação em nuvem serão mais presentes e convergentes. Do ponto de vista prático, não só a fusão dos dois setores no Ministério de Ciência, Tecnologia, Inovações e Comunicações (MCTIC), mas também o claro direcionamento da atuação desse Ministério para o setor de banda-Larga, Internet das coisas e das TIC, sendo as últimas aqui entendidas como o conjunto de aplicações aliadas à infraestrutura de banda larga.

\section{Convergência das Telecomunicações com a Informática}

Antes de direcionar nossa atenção para a fundamentação da perspectiva de uma Sociedade de Serviços em uma economia digital, faz sentido rever, pelos menos, duas proposições de convergência a serem comprovadas: 
i. A primeira proposição diz que as Telecomunicações e , a Informática, serão mais mediadas e partes de uma mesmo serviço. Embora a percepção disso possa ficar mais nítida com o passar dos próximos anos, levando a alterações na percepção do usuários, na identidade de suas áreas e nas experiências acumuladas das organizações.

ii. A segunda proposição diz que os campos de conhecimento das engenharias de telecomunicações, e Informática, agora como Tecnologia da Informação e Comunicação - TIC, tendem a aproximar no uso intensivo das Ciências Exatas, como Matemática, Física, Estatística, e Computação, ou delas tomar parte, com base em outros pressupostos, e.g., a interdisciplinaridade e a transdisciplinaridade.

\section{A comunicação ubíqua e o hibridismo favorecendo os serviços}

O hibridismo que os usuários desejavam tanto nos anos oitenta aconteceu há bem pouco tempo. Antes, o formato ou conteúdo físico de uma mensagem de um fax não era cambiável para passar ao mesmo texto em equipamento de Telex (telegrama), e vice-versa. Os recentes textos enviados nos correios eletrônicos, na mesma década, teriam que ser digitados na máquina de fax ou de telegrama, e vice e versa, mas isto já é coisa do passado. A geração de jovens de quase-tudo-no-meio-digital já é uma realidade: música, imagem, som e vídeo digitalizados transitam com facilidade pelo meio. A convergência e o hibridismo trouxeram profundas mutações na sociedade, visíveis após 30 anos, em 2010.

A comunicação em massa está em pleno processo de transformações que, com base na evolução dos modelos de comunicações, evoluíram rapidamente para atender as relações humanas com maior interatividade, mediadas por TIC, de todos para todos (MIRANDA; SIMEÃO, 2014). Outra mudança significativa, em curso, ficou demonstrada pelos movimentos sociais desde o mundo árabe até as praças econômicas de Nova York; movimentos estes que ganham amplitude graças ao suporte das tecnologias computacionais e TIC.

O uso, a produção e a distribuição da informação mudam, nas práticas de logísticas dos países da Europa e América do Norte. Já o oriente aproxima-se do ocidente. Os tigres asiáticos já viviam a nova realidade, no início do Século XXI, e terminam por servir de parâmetros comparativos (benchmark) ou comparações nas cobranças dos usuários brasileiro. 
O fato é que os países em desenvolvimento, abaixo do Equador, continuam insistindo com uma burocracia resistente às reformas estruturais e operacionais. Com isso, os custos das transações e serviços dos países da América Latina não declinam como desejam os clientes, devido a baixa eficiência e eficácia dos processos e da incompetência informacional do fator humeno, como por exemplo o Brasil (CASTELLS et al., 2007).

Da mesma forma que as mudanças oriundas de convergência, hibridismo e comunicação condicionaram transformações nas formas de conhecimentos, a mesma mutação em curso levará a revoluções científicas, tecnológicas e sociais. Pierre Lévy, (2014, p. 449), fala da possível contribuição dos computadores e das TIC para renovação das ciências humanas, e, ainda, fala da "cultura estudada pelas humanidades e pelas Ciências Sociais, quer dizer, da inteligência coletiva".

A Sociedade Contemporânea, que se caracteriza por um protagonismo do conhecimento, mais explícito e com maior alcance de usuários, diz respeito aos seguintes aspectos: o final da revolução informacional; as ecologias pluralistas da comunicação; os requisitos para a prática do pensamento computacional para mais pessoas; a explícita desigualdade entre pessoas expostas pelas redes sociais e à Internet; a necessidade de respeito à diversidade cultural, a busca da representatividade política e a baixa qualidade ou a falta dos serviços básicos reivindicados por todos.

A situação atual de uma pluralidade de culturas interagindo na rede digital tem o potencial para criar uma nova forma de universalidade ética pluralista a que alude a pergunta: de que espírito se trata? (CAPURRO, 2010). ${ }^{4}$

Afinal que insatisfação, que inquietação ou reclamações levaram o povo às ruas? Os jornais noticiavam que eram questões relacionadas aos problemas de serviço: saúde, educação, e segurança e, principalmente, a descoberta de uma nova forma de se fazer representar (CASTELLS et al., 2007).

\section{Novas causas políticas, ambientais e ecológicas, diretos humanos e educação}

Os movimentos sociais recentes ganham amplitude graças ao suporte das tecnologias computacionais e TIC, seja pela fácil interatividade e fácil mobilização ou pela participação

\footnotetext{
${ }^{4}$ Tradução livre do autor: La situación actual de una pluralidad de culturas que interactúan en la red digital tiene la potencialidad de crear una nueva forma de universalidad ética pluralista a la que alude la pregunta ¿de qué espíritu se trata?
} 
de camadas com indignação e esperança nas redes sociais, onde agregam-se grupos com interesses e preocupações em comum. Uma realidade que se apresenta um pouco diferente dos movimentos como o francês, de 1968, e saem dos modelos tradicionais de luta de classe operária da Europa e das Américas, para abrigar novas causas políticas, ambientais e ecológicas, diretos humanos, educação, arte cultura, e. ainda, reivindicar serviços de melhor qualidade (CASTELLS et al., 2007).

A maior parte das manifestações, nos países em regime democrático das Américas, gravitava em torno das questões de demandas de serviços pela sociedade, para os quais não se tem grandes respostas, a não ser as respostas derivadas da forma como o estado continua atuando: como no século passado. Nos países em regime de exceção, os movimentos tiveram focados na busca dos direitos políticos. O estado está ainda compartilhado ou departamentalizado, é pouco eficiente e trabalha com segmentos isolados.

No Brasil, e em três continentes, nos últimos 4 (quatro) anos, tivemos manifestações e movimentos sociais. Essas manifestações aconteceram mais fortemente em junho de 2013, quase sempre organizadas, majoritariamente, com apoio das redes sociais e outros meios da Internet, associadas às mídias tradicionais. Nessas manifestações, emergiram as questões contemporâneas das sociedades ocidentais, que eram quase sempre focadas nas necessidades do cotidiano das pessoas.

Os cientistas e políticos, da direita à esquerda, fizeram várias leituras diferentes dos movimentos. Entretanto, essas leituras tinham um denominador comum: a baixa qualidade ou falta de serviços públicos e a pouca eficiência do Estado em regular os prestadores de serviços privados. Vale destacar que nas faixas e nos cartazes portados pelos manifestantes constavam palavras e expressões de ordem como: 'a saúde não funciona'; 'a cidade não tem mobilidade'; e 'a classe política está insensível aos pleitos da sociedade". Ao se voltar o olhar para o ponto de vista do consumidor, as maiores reclamações são direcionadas para serviços regulados pelo Estado, tais como: 'planos de saúde privada'; 'empresas de transporte aéreo'; 'os volumosos lucros dos bancos'; 'o desemprego na Europa' e 'falta de mão-de-obra qualificada na América Latina e Caribe'.

$\mathrm{Na}$ maioria das vezes, as análises dos movimentos foram fatiadas e superficiais, focando apenas nas reivindicações das pessoas que foram para as ruas reclamar de quase tudo. Perde-se assim a capacidade de olhar o indivíduo na sua totalidade e contexto e de demonstrar que o Estado ainda não teve a capacidade de entender tudo isso. Embora a inclusão digital e o e-gov , como políticas públicas, já não estejam sendo cobrados com ênfase como o foi há 10 (dez) anos, no entanto, como ressalta Becker (2009, p. 163), e-gov e ciberdemocracia (e- 
cidadania) "são as duas faces de uma mesma moeda e, sem o acesso à rede, é o próprio direito à cidadania que está sendo negado à maior parte da população.“

Muito embora excepcionalmente antigo, o conceito de ciberdemocracia foi retomado no fim no século XX e, recentemente, na virada da década, ele ressurgiu com um vigor deslumbrante, principalmente em virtude do aumento de sentido da concepção de justiça social e o suporte que as inovações tecnológicas a ele propiciaram.

Com base nos pontos levantados no item anterior, logo percebe-se que a e-cidadania deve aumentar a sua abrangência de local para nacional ou internacional, pois o direito à informação e à comunicação perpassa quase todos os movimentos e territórios. O que é a própria definição de território informacional. As ações ou movimentos atuais no ciberespaço, como as intervenções e reivindicações sociais se diferenciam de outros movimentos pragmáticos e imediatistas (preço de um serviço público, por exemplo). Hoje, a estes se acresceram movimentos de longo prazo, mais ecológicodd, comp or exemploe, utilização de animais pelas indústrias, cosméticas, que são v. propostas singulares que conquistam um pequeno ou grande grupo (SANTAELLA, 2013, p. 103).

\section{Uma internet semântica - Web 3.0}

Os visionários e os que ganham dinheiro com a venda de tecnologia e seus serviços adoram fazer previsões. Porém, algo inusitado sempre acontece, como por exemplo, a Web 1.0 se caracterizou melhor, com a chegada e a diferenciação com a Web 2.0. Embora tentadora, a prática de prognosticar dias vindouros jamais deixou ser um terreno movediço. Cabe ressaltar, algo semelhante acontece hoje com as tentativas de caracterização da Web 3.0. A apropriação dos indivíduos com esta tecnologia poderá sofre alterações não esperadas nessa caracterização hoje utilizada.

A computação em nuvem, entendida como a possibilidade do fornecimento de recursos de computação à distância, é uma tendência que fortalece a chegada da Web 3.0, mas isto acontece de modo menos célere devido ao uso de recursos tecnológicos na computação em nuvem.

Quando discutimos se o melhor é usar DropBox ou Google Drive (computação em nuvem), não questionamos o armazenamento e/ou o processamento de dados, mas sim a melhor prestação de serviços. Por exemplo, a segurança dos dados pessoais ou proteção dos grandes projetos complexos sofrem ameaças com mais acesso via Internet, mesmo que exista uma rede corporativa (SANTAELLA, 2012, p. 43). 
O que é comum, no entanto, é a ideia de que o serviço pode ser fornecido sem levar em conta a localização do cliente. A nuvem permite que os usuários tenham acesso aos serviços de qualquer lugar, desde que equipados de navegador Web com conexão à Internet.

Os indivíduos, comunidades e organizações caminham para custear apenas os serviços que usam, e não o rateio das estruturas que lhes oferece o serviço, revendo costumeiro papel de proprietário para apenas usuários do serviço. Esses tipos de comportamentos já são amplamente aceitos pelos usuários domésticos e pequenas empresas de telecomunicações e de informação e, aos poucos, vão ganhar espaço em outras partes da economia. A meta parece ser voltar-se a oferecer serviços diretamente aos usuários, e consequentemente, aumentar a possibilidade de utilização de computadores ou outros equipamentos menos ou mais potentes que possam conectar-se todos via Web.

De ninguna manera preconizo que la comprensión digital del mundo sea la verdadera sino una perspectiva posible, pero sí característica de nuestra ciencia y vida actual, aunque sería un grave error pensar que essa predominancia es igual en todas las culturas y mucho menos que ella es entendida como tal por la mayoría de los seres humanos (CAPURRO, 2010).

\section{TIC para empresas da economia digital e para educação}

A professora Lucia Santaella (2013) foca as repercussões dos processos de comunicação ubíqua na cultura e na educação, para afirmar que eles se realizam em situações fluídas, em múltiplas camadas e não apenas no interior das redes, como também nos deslocamentos espaço-temporais efetuados pelos indivíduos. Voltando-se à perspectiva do aluno e do professor na nova sociedade, tenta-se responder à pergunta título do artigo de Ally e Prieto-Blázquez, (2014) What is the future of mobile learning in education? (Qual é o futuro da aprendizagem móvel na Educação?).

O atual modelo educacional está desatualizado porque foi desenvolvido antes do advento das tecnologias de informação e comunicação. O modelo atual, baseado na transferência prestação presencial face-a-face em sala de aula, é orientado para educar um determinado segmento da população. ${ }^{5}$

Quase sempre é nas escolas e nas universidades que tudo se inicia, os estudantes preparam-se para alavancar as mudanças enquanto não têm contato com a realidade. Isso

\footnotetext{
${ }^{5}$ Tradução livre de: The current educational model is outdated because it was developed before the advent of information and communication technologies. The current model, based on classroom-based face-to-face delivery, is geared towards educating a certain segment of the population.
} 
mudou, um o lay-out desejado para uma sala de uma escola ou universidade, e saindo-se do cenário monótono de um único professor e fileira de carteiras de estudantes anotando em seus cadernos para fazerem provas. (http://www.tonybates.ca/2014/01/12/2020-vision-outlook-foronline-learning-in-2014-and-way-beyond/)

O certo é que nossas vidas, de jovens a idosos, transitam de uma Sociedade pósIndustrial para uma Sociedade de Serviços, evidentemente, passando pelo surgimento da informação em massa e do crescimento do fluxo informacional em todos segmentos da sociedade, da formação da inteligência coletiva, e do aprendizado dentro e fora das escolas, de maneira geral e heterogênea. Ainda, Ally e Prieto-Blázquez, (2014):

\begin{abstract}
Além disso, os professores estão sendo treinados para o modelo atual de educação e, portanto, continuarão usando o modelo quando se tornarem professores. A formação de professores deve ser reinventada para preparar os professores para o sistema educacional tecnologicamente assistido. ${ }^{6}$
\end{abstract}

Os executivos e o mundo empresarial continuam usando modelos que eles aprenderam nas universidades? Esses, compulsoriamente, já fazem a mudança para a concorrência internacional, por exemplo, para computação em nuvem e para os arranjos econômicos que correm para oferecer serviços com base nessa tecnologia. Mas porque isto é significativo? Simplesmente, porque não só os serviços de informação, a democracia e a política são mediados pela tecnologia digital. Também, os processos financeiros, os serviços médicos e de saúde e muitos outros. A lista vai crescendo com a convergência, o hibridismo e a mobilidade fortalecendo a economia digital.

Para sobreviver na economia digital, as empresas passaram a ser utilizadoras de TIC (redes sociais, por exemplo), não apenas TI (sistemas de informação) para processos operacionais e administrativos, mas também, nas relações com o mercado e com os usuários de seus serviços. Isso ocorre, do mesmo modo, nas negociações com os empregados, pois todos dispõem de acesso imediato, pelos smartphones, às mais diversas informações que lhe são relevantes. Os sistemas de informação inteligentes, já de uso em larga escala, devem unificar e fortalecer saberes como a Web 3.0 dentro das organizações.

\footnotetext{
${ }^{6}$ Tradução livre de: Also, teachers are being trained for the current model of education, and will therefore continue using the model when they become teachers. Teacher training must be re-invented to prepare teachers for the technology-enhanced educational system.
} 
O Airbnb, o Uber ${ }^{7}$ e tantas outras soluções inovadoras continuarão acontecendo nesta década, sempre impondo mudanças na realidade dos preços, nas formas mais imediatas de oferecer serviços e objetivando reduzir impostos. E a legislação vai ter que se adaptar, com os governos mantendo seu papel de regulação sem perder impostos. A necessidade de formação além das universidades, a inovação tecnológica, a Web Semântica e os serviços de TIC de grandes corporações somados reforçaram a realidade e fortaleceram a economia digital. E, como tudo não são flores, esse processo traz em seu bojo as desigualdades, o desemprego e a exclusão nas periferias das metrópoles.

O que aponto para o futuro, em termos de configuração da sociedade, é a confirmação do conhecimento ampliado e a presença das TIC como pano de fundo, ou mesmo, como função protagonista do cotidiano das empresas e das políticas públicas. Mas Masi (2013) retrata isso como requisito para nova cidadania (e-cidadania) e vaticina a competência em informação como figura de mérito:

No plano social, emerge a necessidade de superar, através da meritocracia e igualdade de oportunidades, a configuração tradicional das democracias ocidentais, a angustia da família cristã, os grupos de interesse, o egoísmo liberal, o materialismo marxista.

Uma sociedade com forte predominância de serviços se apresenta, basta um olhar para um futuro próximo, uma vez que os passos desse caminhar começam a ficar mais nítidos, embora retardados por uma pausa para controle do crescimento exacerbado do fluxo informacional. E esse é um dos focos desse texto. O outro foco são as novas perspectivas que se abrem, com a dimensão histórica e a ampliação do conceito de cidadania e sua presente relevância.

\section{Cenários econômicos em um breve futuro}

As empresas de TI, principalmente, que ganham dinheiro com a venda de tecnologia e os serviços que lhe é inerente adoram fazer previsões em grandes eventos, mas algo pitoresco sempre acontece, passados 5 anos, algumas das previsões, de fato, aconteceram e outras, não, uma vez que os protagonistas sempre colocam apenas o lado otimista do produto ou da solução de serviço, deixando de fora outras variáveis importantes. Algo sempre se modifica nos cenários propostos para a sociedade, levando os homens a saírem de suas zonas de

\footnotetext{
${ }^{7} \mathrm{O}$ site do Airbnb é https://www.airbnb.com.br/); o do Uber, https://www.uber.com/pt-BR/.
} 
conforto, devido, por exemplo, a fatores como uma maior disputa por alimentos, como a deterioração do meio ambiente e a escassez de bens e serviços como o Painel Telebrasil, anualmente, apresenta (http://paineltelebrasil.org.br/ edições 2013; 2014 e 2015).

Tanto faz, ser a produção de TI voltada para uma inovação alimentícia, uma solução de automação industrial, para os cuidados com a saúde, para com a segurança, transporte ou mesmo para a preservação do meio ambiente, as possibilidades de fracassos não evidenciadas pelos futuristas têm um certo grau de probabilidade de ocorrência. $\mathrm{O}$ fato é que, após um período curto, chegaremos à sociedade com base na agricultura de larga escala e familiar de subsistência, a uma indústria mais automatizada, e a governos, comércio e terceiro setor centrados em serviços; situação que se confirma a cada dia.

Os centros de excelência e organismos como a ONU e a UNESCO, por exemplo, voltaram-se a chamar as atenções para riscos e oportunidades da nossa sociedade contemporânea. E fazem isto para que foquemos, na terceira década do século XXI, na predominância dos serviços, de muitas mudanças na economia, nos campos social, político e na cultura e lazer.

\section{O que esperamos com a Agricultura 5.0?}

Existem muitas iniciativas para produzir proteína de outras fontes menos tradicionais, mais fáceis de extrair e de forma mais econômica, como o uso de algas, planctos e insetos, por exemplo, e uma intensa atenção para o mercado crescente de alimentos saudáveis. Essas novas fontes podem fornecer mais proteína que as atuais, como a carne bovina, sendo rotuladas como fontes alternativas de proteínas sustentáveis. Os carboidratos foram um ganho da Agricultura $4.0^{8}$ e deve-se usar tecnologias de informação para atender melhor os princípios de uma dieta mais saudável. A questão ficará entre o racional e o paladar, entre a cultura e o econômico. Atualmente, cerca de $30 \%$ de todas as superfícies agriculturáveis no mundo são ocupadas pela criação de animais para abate. Imagine se tais espaços deixarem se ser usados dessa forma, e as grandes empresas passarem a usá-los de forma mais inteligente como é esperado na Agricultura 5.0, após a sua quarta revolução já em curso.

\footnotetext{
${ }^{8}$ A tecnologia de informação é um caminho sem volta no mundo rural, que já vivencia a chamada "Agricultura 4.0", baseada na produção digital. A afirmação é da chefe-geral da Embrapa Informática Agropecuária, Silvia Massruhá, no painel "Agricultura digital: da biotecnologia ao big data, a agricultura moderna e globalizada", durante o $4^{\circ}$ Foro de Agricultura da América do Sul/Agrooutlook, na sexta-feira, 26/08 https://www.embrapa.br/busca-de-noticias/-/noticia/15894563/agricultura-40-a-agricultura-conectada
} 
Os país desenvolvidos já direcionam suas agriculturas para isto. As plantações no norte da Alemanha com o uso racional do solo e a sustentabilidade Isto é possível pelo contínuo uso da TI, e isto significa o uso de robôs em larga escala pelo agricultor, quando, no futuro, o baixo custos desses artefatos forem menores de 1.000,00 dólares. Nesses cenários, os agricultores do Terceiro Mundo poderão tornar-se gerentes das suas terras ao invés de trabalharem nelas todos os dias e explorarem a mão-de-obra humana. As formas de plantar e extrair já passam por processos que economizam água, são mais ágeis com fontes alternativas de energia, no intuito de se -se produzir o mínimo de lixo e o máximo de restos reaproveitáveis.

Os alimentos proteicos produzidos in vitro já estão disponíveis e irão se tornar mais baratos que os naturais. Isso sem mencionar que, já ao redor de 2018, sacrificar bovinos, para nova geração que toma conhecimento dos processos de ética questionável da indústria alimentícia, será controverso, para dizer o mínimo. Ser vegano, em 2021, será uma opção tão banal como é hoje ser vegetariano.

No Brasil, nos últimos 16 anos, enebriados por um sonho de consumo, consumidores imaginaram que bastaria ter acesso aos bens e serviços, produtos eletrodomésticos, casa própria, viagens de férias, e bom celular para realizar a expectativa de alcançar uma classe mais alta. Os avanços foram significativos na ampliação da educação universitária e técnica, assim como na na produção científica; mas a qualidade continuou a deixar a desejar.

No capitalismo ou socialismo, alguém tem que pagar a conta, seja individual, familiar ou coletiva. No Brasil, o processo de incentivar o consumo para superar a crise mundial trouxe um ganho, mas acabou no exato momento que a dívida pública cresceu e passou a ser um empecilho aos gastos sociais, e que trouxe a prática das contabilidades artificiais. Os valores da dívida pública se aproximam rapidamente da incrível marca de R\$ 3 trilhões. E os altos juros, para manter o atrativo do capital, de uma dívida dessas proporções, estão inviabilizando muitos projetos, em um pais fortemente produtor de alimentos (commodities), e irá sacrificar serviços como saúde, educação, e outros que trazem bem-estar e direitos de cidadãos.

\section{Pode-se automatizar ainda mais a Indústria 4.0?}

As revoluções ocorridas na indústria, foram bem mais visíveis que na agricultura. Dessa primeira revolução até a atual, essas conquistas beneficiaram centros de pesquisas e de inovação. Tanto faz se nas grandes indústrias - automobilística, naval e aeroespacial - assim 
como na microeletrônica, houve sempre o uso crescente de tecnologia. O que os pesquisadores dos campi universitários americanos e europeus, e em alguns países asiáticos, prenunciaram para os cenários no início do século XXI foi que a indústria se apropriaria dos novos conceitos que surgem para explorar novas oportunidades de negócios e soluções tecnológicas, aplicando-as em bens e serviços a partir desses conceitos e, depois, usar inteligência artificial embarcada alocando-a na planta produtiva da indústria, por exemplo, em robôs. A Indústria 4.0 ou Quarta Revolução Industrial, é um termo que engloba algumas tecnologias para automação e troca de dados e utiliza conceitos de Sistemas ciberfísicos, Internet das Coisas e Computação em Nuvem (https://pt.wikipedia.org/ wiki/Industria_4.0).

A competência em informação tecnológica trouxe um fator de competitividade, manteve a qualidade e uma incipiente preocupação com o meio ambiente. Agora, foca-se nas interfaces dos dispositivos, tangíveis e adaptáveis, por exemplo no ambiente doméstico, ou melhorando a interface entre o passageiro de um voo tornando mais amigável a complexidade de um avião de último modelo. O paradox do mesmo homem, usando e apropriando-se de novos conceitos, recursos e conhecimentos, como e-book, evitando-se oposto, um homem cibernético usando recuros antigos. $\mathrm{O}$ fato é que novos conceitos que surgem para explorar novas oportunidades de negócios e soluções tecnológicas. Vide Singularity University (https://su.org), 2016.

Se de um lado esses enormes avanços e a automatização de funções repetitivas (ou de funções com exigência de maior esforço físico) irão melhorar a qualidade de vida de quem vier a se beneficiar desses avanços tecnológicos (e.g., a classe média das sociedades centrais do capitalismo mundial), de outro lado os substituídos, possivelmente, serão arremessados para maior desemprego e crescente marginalidade. Isso será especialmente notado se tratarem-se de pessoas com idade acima de 60 anos; esses e outros substituídos serão os novos excluídos, todos eles trazendo agora o amargo gosto de já ter experimentado, parcialmente, a inclusão.

A título de exemplificação, pensamos no cenário dos veículos autônomos. Em 2018, os primeiros veículos dirigidos automaticamente aparecerão em público. Ao redor de 2020, a indústria automobilística completa começará a ser demolida. Em 2030, a indústria alemã não produzirá carro a combustão de petróleo, ou emissores de poluentes. Você não desejará mais possuir um automóvel. Nossos filhos jamais necessitarão de uma carteira de habilitação ou serão donos de um carro. Isso mudará as cidades, pois necessitaremos de 90-95\% menos carros para isso. Poderemos transformar áreas de estacionamento em parques. Cerca de 
1.200.000 pessoas morrem a cada ano em acidentes automobilísticos em todo o mundo. Temos agora um acidente a cada $100.000 \mathrm{~km}$, mas com veículos autodirigidos isto cairá para um acidente a cada 10.000.000 de $\mathrm{km}$. Isso salvará mais de 1.000 .000 de vidas a cada ano (https://www.ibm.com/blogs/robertoa/2016/07/a-4a-revolucao-industrial-esta-em-curso/)

\section{Vivemos em uma Sociedade de Serviços 3.0?}

Há 10 anos atrás, ao ter-se perguntado sobre o que o que aconteceria após a Sociedade da Informação em Rede, obter-se-ia como resposta: uma Sociedade de Serviços. Aproximamo-nos de uma Sociedade de Serviços plena como indicam alguns cenários. Ou, diferentemente, como alguns outros profetas insistem, uma economia digital com predominância em serviços. O fato é que ter um carro para ir todo o dia para o trabalho, manter a casa para veraneio ou guardar uma parafernália de produtos dentro de casa pode ser uma opção agora questionável. Os serviços foram surgindo e aumentando em todas as partes da economia local e global, das tarefas cotidianas à formação escolar ou profissional. Mesmo setores mais conservadores passaram a ver no serviço uma opção vantajosa. Alguns estudos e pesquisas já apontam isso com clareza. Vejam-se os chamados new financial models, (pagase pelo que se usa e não pela propriedade) que já acontecem com os serviços de educação e se espalhando, de forma análoga, com outros serviços (BATES, 2014).

Respondendo ao título desta seção, de fato, um cenário com a presença maciça dos serviços na economia será uma realidade, até o final desta segunda década. Nossa observação iniciou-se nos primeiros meses de 2008, nos EUA, tendo continuado por dois anos, na Europa e América Latina, confirmando essa tendência de serviços por todos os lados. Mas foi no final da década passada, que os países asiáticos perceberam os serviços como negócios, inclusive na alocação de sua farta mão-de-obra barata.

Quando chegaremos à Sociedade de Serviços 3.0? O que já existe hoje em termos de serviços que esteja nos moldes de uma Sociedade de Serviços 3.0? Entende-se que a Sociedade de Serviços 3.0 não esteja ancorada apenas na esfera semântica de Pierre Levy (2014), como apontam outros centros de pesquisa. Esses centros investigam o que acontecerá depois da Web 2.0. Mas, seguramente, a Web Semântica poderá ser um fio condutor para a Sociedade de Serviços 3.0. Junte-se a isto as perspectivas para exercícios da e-academia pelos indivíduos em suas comunidades, como é citado em Citizens as Actors (HARVARD, 2013).

No momento, faz-se necessário amadurecer as ideias e indagações aqui formuladas a respeito das perspectivas futuras da Sociedade de Serviços 3.0 e, no entanto, percebe-se que a 
sociedade, a cada dia, desloca-se da pesada e sólida sociedade pós-industrial, com o conceito de possuir bens para sempre, para um outro entendimento: o de, simplesmente, usá-los.

La dimensión de la privacidad y su correlato, lo público, no es algo obsoleto perteneciente a la sociedad burguesa, sino que es una constante de la existencia humana con diversas posibilidades de transformarse de acuerdo a diferentes marcos históricos, sistemas políticos y económicos y tradiciones culturales (CAPURRO, 2010).

Paralelamente a isso, consolida-se o crescimento da inteligência dos sistemas de informação, até mesmo dos controles sobre o cidadão, e espera-se então que o sujeito vá recebendo do seu contexto mais possibilidades para exercer sua e-cidadania, junto com o direito de acesso aos serviços e à democracia participativa.

As empresas prestam serviços com base em agentes e sistemas de informação inteligentes. A partir desse momento as informações poderão fazer parte dos sistemas dos centros de informação. Isso na verdade envolveum risco real, uma vez que esses sistemas poderão manipular milhões de informações pessoais, ao mesmo tempo, à revelia do usuário (MEDEIROS NETO, 2013).

Evidentemente que isto não é garantido, pode ser que a ordem seja alterada, e certas questões de preservação do meio ambiente alterem o curso da história e que os modelos econômicos mudem suas premissas. Vivem-se, ainda, muitas desigualdades de acesso às informações, bens e serviços. Se tivemos uma pausa na era da informação, dos incontroláveis fluxos informacionais e dos big data, eles ainda não se consolidaram, só para citar dois fatores, isso ficou bem marcante nessas duas últimas décadas.

Evidentemente que, enquanto a exclusão digital e social não for pelo menos amenizada, como por exemplo nos países mais pobres da América Latina e Central (e.g., o Haiti), as ideias de cibersociedade, ciberdemocracia e de e-cidadania continuarão a ser letra quase morta para esses que estão do outro lado do muro virtual. Ao passo que o crescimento da conectividade e/ou formação da inteligência coletiva no ciberespaço, a revolução da educação das instituições de ensino, a inovação constante nas indústrias do conhecimento e nas organizações, afetaram a economia, com possibilidades de chegar-se a uma economia menos mercantilista e mais digital. Certamente, que tudo isto acarretará desenvolvimento humano. Mas nada garante a vitória da luta da redução das desigualdades sociais e da pobreza, que se almeja com a e-cidadania.

Para que isso se torne imperativo moral, há a necessidade de alguns pré-requisitos: (i) acesso às TIC regulado em relação à competividade internacional; (ii) melhores condições 
para o desenvolvimento da ciberdemocracia; (iii) um marco regulatório para Internet e serviços de TIC e (iv) espaço para desenvolvimento e conscientização da e-cidadania nas escolas e nas organizações governamentais e não-governamentais (LEMOS; LEVY, 2010, p. 151).

E como perspectiva final para fortalecer as duas proposições citadas anterioriormente, observa-se nitidamente que:

i. $\quad$ As redes de telecomunicações e a computação em nuvem serão mais presentes e convergentes no final da segunda década do século XXI;

ii. As redes integrar-se-ão além do humano, ou melhor, conectarão as coisas para servir o cidadão; as empresas que detêm os meios ou canais de comunicação sonham com os conteúdos, e as que tratam dos conteúdos querem os meios de comunicação;

iii. Os dispositivos móveis inteligentes caminham para universalização, a posse desses dispositivos dobra a cada dois anos nas mãos das pessoas, mesmo entre os usuários de baixa competência em informação;

iv. Os sistemas de informação serão mais inteligentes e integrados às diversas redes, possibilitando a oferta de serviços personalizados e amigáveis;

v. As TIC permearão quase todas as áreas de conhecimento e das atividades humanas;

vi. $\quad$ A Internet Semântica (Web 3.0) irá mostrar a sua cara e dará as regras do jogo no final da década; como por exemplo, o aprendizado ao longo da vida, com base na aquisição das competências em comunicação e informação para inclusão social;

vii. A gestão do conhecimento colaborativa propiciará mais inteligência para prestação dos serviços e muitos outros aspectos das atividades humanas.

Com mais segurança física e virtual, o que foi exposto nos leva a mudar, compulsoriamente, as expectativas dentro das comunidades vulneráveis, com o desenvolvimento de novas formas de viver em sociedade, com os novos problemas e desafios diagnosticados, mas longe de ser um paraíso dourado, mesmo com intensa presença de tecnologias e da insistência dos visionários. 


\section{Referências}

ALLY, M. \& PRIETO-BLÁZQUEZ, J. (2014). What is the future of mobile learning in education? Mobile Learning Applications in Higher Education [Special Section]. Revista de Universidad y Sociedad del Conocimiento (RUSC). Vol. 11, No 1. pp. 142-151. doi http://dx.doi.org/10.7238/rusc.v11i1.2033.

BATES, A. W. 2020 Vision: Outlook for online learning in 2014 and way beyond -2014. Disponível em: http://www.tonybates.ca/2014/01/12/2020-vision-outlook-for-online-learningin-2014-and-way-beyond/\#sthash.A5OzwTuu.dpuf.

BAUMAN, Zygmunt. Modernidade Líquida. Rio de Janeiro. Jorge Zahar Editor. 2001.

BECKER, Maria Lúcia. Inclusão Digital e Cidadania - As possibilidades e as ilusões da solução tecnológica. Ponta Grossa: Ed. UEPG. 2009.

BUCKLAND, Michael K. Information as thing. Journal of the American Society for Information Science and Technology, v.45, n.5, p.351-360, June 1991. Disponível em: <http://people.ischool.berkeley.edu/ buckland/thing.html>. Acesso em: 30 jan. 2015.

CAPURRO, R. Ensayo autobiográfico en diálogo con Prof. Rafael Capurro. Perspectivas em Ciência da Informação, v. 15, n. 3, p. 255-272, set./dez. 2010. Disponível em: http://portaldeperiodicos.eci.ufmg.br/index.php/pci/article/viewFile/1190/792. Acessado em 26 de novembro de 2016.

CASTELLS, M.; FERNANDEZ-ARDÈVOL, M.; QIU, J. L.; SEY, A. Comunicación móvil y sociedad. Una perspectiva global. Ariel-Fundación Telefónica. 2007. Disponível em http://www.eumed.net/libros/2007c/indice.htm. Acessado em: 29 de outubro de 2012.

CUEVAS-CERVERÓ, A.; MARQUES, M.; PAIXÃO, P. B. S. (2014) A Alfabetização que necessitamos: informação e comunicação para a cidadania. Informação \& Sociedade Estudos, João Pessoa, v.24, n.2, p.35-48, maio/ago. 2014.

FRANÇA, A. C. O.; STIUBIENER, I. O Uso de Dispositivos Móveis para Otimização da Difusão da Informação nos Ambientes Virtuais de Aprendizagem. 2015. VIII World Congress on Communication and Arts, April 19 - 22, 2015, Salvador, Brasil. Acessado em: 26 de novembro de 2016.2 Disponível em http://copec.eu/congresses/wcca2015/proc/works/33.pdf.

FRAGOSO, S.; RECUERO, R.; AMARAL, A. Métodos de pesquisa para Internet. Porto Alegre: Sulina. 2011. 
HARVARD, University. Internet Monitor 2013: Reflections on the Digital World. http://h2o.law.harvard.edu/playlists/5129.

JUNQUEIRA, A. H.; PASSARELLI, B. \& GUZZI, D. Conexões sem fio à Internet, mobilidade urbana e convergência digital: estudo de caso nos telecentros do AcessaSP. In: PASSARELLI, B; SILVA, A. M.; RAMOS, F. (Orgs.). E-Infocomunicação. São Paulo: Senac. 2014.

KUMAR, K. Da Sociedade Pós-Industrial à Pós-moderna - Novas teorias sobre o mundo contemporâneo. Rio de Janeiro: Jorge Zahar E. 2006.

LEMOS, A.; LÉVY, P. O futuro da Internet, em direção a uma ciberdemocracia planetária. São Paulo: Paulus. 2010.

LEMOS, A. (2014) Mobile Communication and New Sense of Places: a critique of spatialization in cyberculture. Em Galaxia, n. 18, dezembro de 2008, SP, PUC-SP., ISSN. 1519311X., pp. 91-108. Acessado em 12 dezembro de 2014. Disponível em http://revistas.pucsp.br/index.php/galaxia/article/view/1914/1177

LÉVY, P. A esfera semântica. Tomo 1: computação, cognição e economia da informação. São Paulo: Annablulume. 2014.

MASI, D. O Futuro Chegou - Modelos de vida para uma sociedade desorientada. Rio de Janeiro: Casa da Palavra. 2013.

MEDEIROS NETO, B.; MIRANDA, Antonio. (2015) Modelo de evaluación de la inclusión digital, informacional y social - MAVIDIS - de usuarios de la sociedad de la información apoyado em los indicadores y métricas para Brasil Mediação. Revista Ciência da Informação/IBICT. 2015.

MEDEIROS NETO, B. Avaliação dos impactos dos processos de inclusão digital e informacional nos usuários de programas e projetos no Brasil. Tese (Doutorado). Brasília: Faculdade de Ciência da Informação, UnB. 2012.

MEDEIROS NETO, B. Literacias digitais e mediações dos dispositivos móveis em ambientes de vulnerabilidade social (Projeto de Pesquisa). São Paulo: ECA/Universidade de São Paulo. 2013. Acessado em: 13 maio 2014. Disponível em: http://www3.eca.usp.br/sites/default/files/webform/projetos/pos-doc/Projeto\%20BMN.pdf.

MIRANDA, A. L. C. de; SIMEÃO, E. L. M. S. (2014) Da comunicação extensiva ao hibridismo da Animaverbivocovisualidade. Informação \& Sociedade: Estudos, João Pessoa, 
v.24, n.3, p.49-62, set./dez. 2014. Acessado em 13 setembro de 2015. Disponível em: http://www.ies.ufpb.br/ojs/index.php/ies/article/view/19075/12401.

PASSARELLI, B. (2014). Do analógico ao digital \#tudojuntomisturado. Juventude conectada/organização Fundação Telefônica. São Paulo: Fundação Telefônica, 2014. Disponível em: http://educacaointegral.org.br/wp-content/uploads/2014/08/juventudeconectada-online-1.pdf. Acessado em 26 de outubro de 2014.

PIENIZ, M.; SILVEIRA, A. C. M. Apropriações da Web como meio para o exercício da cidadania: expressões de identidades culturais ligadas ao território. In: MORIGI, V. J.; TOURINHO, I. M. G.; ALMEIDA, C. D. COMUNICAÇÃO, INFORMAÇÃO E CIDADANIA - Refletindo práticas e contextos. Porto Alegre: Editora Sulina. 2011.

SANTAELLA, L. Para compreender a ciberliteratura. In: Texto Digital, v.8, n.2, pp. 229240, jul./dez. 2012.

SANTAELLA, Lucia. Comunicação ubíqua - Repercussões na cultura e na educação. São Paulo: Paulus. 2013. 